\title{
Educação Permanente em Saúde para Agentes Comunitários: um Projeto de Promoção de Saúde
}

\section{Continuing Education in Health with Community Workers: a Project of Health Promotion}

\author{
Ana Caroline Seccol, Patrícia Matte Rodrigues², Carolina Sarzi Ledur³, Edinara \\ Zanatta $^{4}$, Caroline Oliveira Mozzaquatro5, Dorian Mônica Arpini6
}

\begin{abstract}
Resumo
Este trabalho objetiva relatar a experiência de um trabalho de educação permanente em saúde realizado com Agentes Comunitários de Saúde (ACS). As ações são realizadas por meio de um projeto de extensão vinculado ao Departamento de Psicologia de uma Universidade Federal do Sul do Brasil. O trabalho vem sendo desenvolvido desde 2013, com periodicidade mensal e conta com a participação dos ACS de uma Unidade Básica, localizada na região norte de um município do Rio Grande do Sul. A proposta tem possibilitado a troca de informações e experiências, por meio da reflexão e problematização, tanto do saber científico quanto da prática profissional. Além disso, pode-se constatar que os encontros têm o potencial de aliviar angústias e promover saúde aos ACS, além de ampliar as possibilidades de compreensão das problemáticas vivenciadas, buscando estratégias para lidar com elas. Destaca-se, ainda, a importância da integração entre a Universidade, a Unidade de Saúde e os ACS.
\end{abstract}

Palavras-chave: Serviços de saúde pública. Promoção da saúde. Educação permanente.

\begin{abstract}
This study aims to report the experience of a proposal of education in health carried out with Community Health Workers (CHW). Actions were done based on an extension project, part of the activities of the Psychology Department of a Federal University in Southern Brazil. Such work is being done since 2013, on a monthly basis, and participants are CHW of a Primary Health Care Unit located in the north side of a city in the state of Rio Grande do Sul. The proposal has enabled sharing of information and experiences through reflection and questioning, regarding both scientific knowledge and professional practice. Moreover, the experience evidences that the meetings have the potential for relieving anxiety and promoting health among CHW, in addition to expanding their possibilities of understanding the problems experienced and finding strategies to cope with them. The study highlights the relevance of the integration among University, Primary Health Care Units and CHW.
\end{abstract}

\footnotetext{
${ }^{1}$ Universidade Federal de Santa Maria, Santa Maria, Brasil. E-mail: ana.caroline.secco@gmail.com.

${ }^{2}$ Universidade Federal de Santa Maria, Santa Maria, Brasil. E-mail: patricia_mr@yahoo.com.br.

${ }^{3}$ Universidade Federal de Santa Maria, Santa Maria, Brasil. E-mail: carolinasarzi@gmail.com.

${ }^{4}$ Universidade Federal de Santa Maria, Santa Maria, Brasil. E-mail: edi.zanatta@hotmail.com.

${ }^{5}$ Universidade Federal de Santa Maria, Santa Maria, Brasil. E-mail: carol.mozzaquatro@gmail.com.

${ }^{6}$ Universidade Federal de Santa Maria, Santa Maria, Brasil. E-mail: monica.arpini@gmail.com.
} 
Keywords: Public health services. Health promotion. Continuing education. 


\section{Introdução}

O Sistema Único de Saúde (SUS) é fruto de uma luta política da qual participaram movimentos populares, associações de moradores, profissionais de saúde e vários outros atores sociais, que por meio do movimento da reforma sanitária buscaram a construção de uma agenda de discussão positiva de direitos sociais (Nascimento \& Correa, 2008). De acordo com o Fórum da Reforma Sanitária Brasileira (Brasil, 2007), o SUS é bem mais que um arranjo institucional, é um projeto civilizatório que pretende produzir mudanças de valores da sociedade, tendo a saúde como seu eixo transformador. Ele se encontra presente na Constituição Federal de 1988 assegurando que toda a população brasileira possa ter acesso ao atendimento público de saúde (Brasil, 2009). No art. 196 da Constituição está posto que "A saúde é direito de todos e dever do Estado, garantido mediante políticas sociais e econômicas que visem à redução do risco de doença e de outros agravos e ao acesso igualitário às ações e serviços para sua promoção, proteção e recuperação" (Constituição Federal, 1988, p. 104).

Em 1990, o art. 198 da Constituição foi regulamentado pela Lei $n^{\circ}$ 8.080, conhecida como Lei Orgânica de Saúde ou Lei do Sistema Único de Saúde, na qual estão instituídos os princípios e diretrizes do SUS, como os da universalidade, integralidade, equidade, descentralização, regionalização e hierarquização e participação da comunidade. A esse respeito, apesar da participação da comunidade estar presente na Lei $\mathrm{n}^{\mathrm{o}} 8.080$ no art. $7^{\circ}$, inc. VIII, ela foi vetada pelo então presidente Collor, sendo necessário mais tarde, no mesmo ano, a regulamentação e homologação da Lei no 8.142/90, que versa especificamente sobre essa temática. No âmbito da hierarquização, ela compreende a forma de organização dos serviços a fim de atender às necessidades de saúde da população de forma mais pontual, prevendo que os serviços de alta e média complexidade sejam atendidos em dispositivos especializados e que as necessidades mais comuns e frequentes da população possam ser resolvidas nos serviços de Atenção Primária à Saúde (APS), conhecidos também como Atenção Básica - AB (Brasil, 2006; Brasil, 2009).

A $A B$ pode ser caracterizada por um conjunto de ações de saúde no âmbito individual, familiar e coletivo, que abrangem a promoção e proteção da saúde, prevenção de agravos, diagnóstico, tratamento, reabilitação, redução de danos, cuidados paliativos e vigilância em saúde. É a porta de entrada preferencial da rede de atenção que deve atender às demandas e necessidades de saúde da população (Brasil, 2017). A atenção básica deve considerar o sujeito em toda sua singularidade e complexidade, observando que ele está inserido em um contexto social, econômico e cultural. Nesse sentido, mediante o exercício de práticas dirigidas a populações de territórios bem delimitados, ela tem como finalidade desenvolver uma atenção integral que tenha impacto na situação de saúde e autonomia das pessoas, considerando a dinamicidade existente no território. Para isso, o Ministério da Saúde definiu a Saúde da Família como estratégia prioritária para a organização e fortalecimento da AB no país (Brasil, 2011b; Brasil, 2012; Brasil, 2017, Motta \& SiqueiraBatista, 2015).

Atualmente o Programa Saúde da Família (PSF) deixou de ser programa e passou a ser 
definido como estratégia permanente na atenção básica, considerando seu caráter de permanência e continuidade (Souza \& Abrahão, 2017). Em seu primórdio, o PSF emergiu no cenário brasileiro buscando uma reorientação do modelo técnicoassistencial. Havia a necessidade de substituição do modelo historicamente centrado na doença e no cuidado médico individualizado para um novo, sintonizado com os princípios do SUS, no qual o foco da atenção fosse a pessoa, não a doença (Gomes, Cotta, Cherchiglia, Mitre \& Batista, 2009). O PSF propunha uma ampliação do lócus de intervenção em saúde, incorporando na sua prática o domicílio e os espaços comunitários diversos. Buscava assim, contribuir para o fortalecimento do vínculo entre profissionais das equipes e a comunidade local, e aumentar o exercício da cidadania, especialmente em camadas pauperizadas da população, garantindo-lhes o acesso aos meios de promoção da saúde (Nunes et al., 2002).

O PSF surge oficialmente no Brasil em 1994, a partir de experiências exitosas, especialmente no estado do Ceará com o Programa de Agentes de Saúde. Este teve início no ano de 1987, quando o governo daquele estado lançou o slogan: "a saúde bate à sua porta", tendo como objetivo primário reduzir os alarmantes indicadores de morbimortalidade infantil e materna, especialmente no Nordeste do Brasil. A partir de 1991, após experiências similares em outros estados, esse programa foi gradativamente se disseminando e passou a ser implementado pelo Ministério da Saúde em todo o território nacional, em parceria com as secretarias estaduais e municipais de saúde, sendo denominado então Programa de Agentes
Comunitários de Saúde (Barros, Barbieri, Ivo \& Silva, 2010; Leite \& Paulon, 2013).

No âmbito do SUS, a profissão de agentes comunitários de saúde foi criada no Brasil no ano de 2002, por meio da Lei 10.507/02, a partir de discussões sobre a identidade e reconhecimento profissional da categoria. Anteriormente o Decreto $n^{\circ} 3.189 / 99$, fixou as diretrizes para o exercício da atividade e a Portaria $\mathrm{n}^{\circ} 1.886 / 97$, aprovou as normas e diretrizes do Programa de Agente Comunitário e do Programa de Saúde da Família. Posteriormente, a Lei n ${ }^{\circ}$ 11.350, de 5 de outubro de 2006, passou a reger as atividades do Agente Comunitário, orientando e normatizando suas práticas, estando em vigência no país até hoje com algumas reformulações (Souza, Barcelos \& Lanza, 2014).

Inicialmente, esperava-se que os ACS fizessem visitas domiciliares às famílias com certa regularidade e, nos casos que detectassem algum problema, encaminhassem a questão aos outros profissionais da equipe (Piccinini \& Neves, 2013). Hoje a Política Nacional de Atenção Básica (Brasil, 2017) orienta que as atividades dos ACS e dos Agentes de Combate às Endemias (ACE) devem estar integradas, uma vez que a $\mathrm{AB}$ e a Vigilância em Saúde devem se unir para identificar problemas de saúde nos territórios e planejar estratégias de intervenção clínica e sanitária efetivas. Desse modo, cabe aos ACS e aos ACE desenvolver atividades de promoção de saúde, de prevenção das doenças e agravos, por meio de visitas domiciliares e ações educativas individuais e coletivas nos domicílios e comunidade, além de orientação às famílias sobre os serviços de saúde disponíveis no território.

Entre as atribuições específicas dos ACS estão o cadastramento das famílias, mapeamento 
da comunidade, coleta de informações que apoiem o diagnóstico demográfico e sociocultural da comunidade, registrar os dados de nascimentos, óbitos, doenças e outros agravos, informar os usuários sobre datas de consultas e exames e buscar a integração entre equipe de saúde e população adscrita (Brasil, 2017). Morosini, Fonseca e Lima (2018) apontam que atualmente há uma predominância de atividades de produção e registro de dados e informações pelas quais somente os ACS são responsáveis. As autoras problematizam que tal situação pode favorecer a descaracterização do trabalho dos ACS, visto que há um direcionamento à realização de ações mais pontuais com o foco na prevenção de doenças, em detrimento das ações de educação em saúde.

Os ACS são muito importantes na implementação do Sistema Único de Saúde e no fortalecimento da integração entre os serviços de saúde da atenção primária e a comunidade (Alencar, Oliveira, Belém, Parente \& Albuquerque, 2015). Nesse sentido, é atribuída a ele a função de estabelecer um elo entre a comunidade e os serviços de saúde, sendo esse elo fundamental para a reorientação do modelo de atenção (Lopes, Durão \& Carvalho, 2011).

Nogueira, Silva e Ramos (2000, p. 10) endossam que os ACS são

[...] um elo entre os objetivos das políticas sociais do Estado e os objetivos próprios ao modo de vida da comunidade; entre as necessidades de saúde e outros tipos de necessidades das pessoas; entre $\mathrm{O}$ conhecimento popular e o conhecimento científico sobre saúde; entre a capacidade de auto-ajuda própria da comunidade e os direitos sociais garantidos pelo Estado.

Nessa perspectiva, Leite e Paulon (2013) apontam que uma das principais apostas nos ACS é a de que eles possam fazer a articulação e mediação entre os saberes científicos e os populares, com a finalidade de construir projetos de cuidados que atendam às especificidades de um determinado território. Ainda, segundo os autores, o capital social do qual os ACS são detentores por serem membros/moradores da comunidade onde trabalham, potencializa a proximidade entre usuários e profissionais, possibilitando o reconhecimento de recursos do território que estão fora do campo sanitário.

Apesar disso, mesmo reconhecendo a importância e potencialidade do trabalho dos ACS, Piccinini e Neves (2013) chamam atenção para a necessidade de se olhar com certo posicionamento crítico para as dificuldades e limites que compõem essa função. Conforme os autores, no interior das casas dos usuários, os agentes têm se deparado com um conjunto de situações imprevisíveis para as quais não há respostas prontas nem soluções simples, existindo, assim, uma série de situações para as quais a área da saúde ainda não desenvolveu conhecimentos nem instrumentos adequados de trabalho e gerência. O trabalho dos ACS compreende desde a abordagem das famílias e indivíduos, o contato com condições de vida precárias, até o posicionamento diante de desigualdades sociais e a busca da cidadania (Silva \& Dalmaso, 2002). Nesse sentido, a ação dos ACS é sempre híbrida, complexa e singular, sendo a necessidade de se pensar ações de educação e suporte para esses profissionais um aspecto 
comum encontrado na literatura científica sobre o tema (Piccinini \& Neves, 2013).

Para Pereira e Oliveira (2013), o processo formativo é inacabado e deve estar em constante transformação, a fim de responder às complexidades e às mudanças dinâmicas da realidade social. Os autores afirmam que, na perspectiva da atenção primária à saúde, é necessária uma formação mais ampla e que esteja de acordo com o contexto local, possibilitando, assim, perfis profissionais que sejam capazes de reconhecer contextos e mobilizar soluções criativas para situações complexas.

Figueiredo (2012) e Davini (2009), da mesma forma, atentam para a importância de se perceber os trabalhadores de saúde como atores reflexivos e problematizadores do próprio fazer, capazes de construir conhecimento e estratégias de ação. Além disso, apontam, também, que a formação dos profissionais de saúde deve adotar estratégias educativas que englobem uma perspectiva humanista, integradora das dimensões pessoal, social e profissional, com competências éticas, políticas e técnicas, capacidade crítica e sensibilidade para que se possa atuar em contextos de incerteza e complexidade.

Nesse cenário, a educação permanente em saúde surge como possibilidade de prática educativa inovadora, pois propõe que

[...] os processos de capacitação dos trabalhadores da saúde tomem como referência as necessidades de saúde das pessoas e das populações, da gestão setorial e do controle social em saúde, tenham como objetivos a transformação das práticas profissionais e da própria organização do trabalho e sejam estruturados a partir da problematização do processo de trabalho. (Brasil, 2004, p. 38)

Assim sendo, o conceito de educação permanente pode ser entendido como uma prática educativa, ancorada no trabalho e no conhecimento prévio dos trabalhadores, na problematização da realidade, na aprendizagem significativa e na transformação das suas práticas (Gigante \& Campos, 2016). A preocupação e o compromisso com a formação e capacitação de recursos humanos na área da saúde não são novos. Vem sendo pensados e estão previstos em diversos dispositivos legais, como a Constituição Federal de 1988, a Lei no 8.080 e a Política Nacional de Educação Permanente. Nelas está posto que a formação e capacitação dos recursos humanos deve estar articulada em cooperação técnica com os órgãos formadores/instituições de ensino, considerando os serviços de saúde como locais de ensino-aprendizagem que expressam essa indissociabilidade. A fim de romper com a formação fragmentada, e reafirmar os princípios do SUS com ênfase na intersetorialidade e na multidisciplinaridade, é que as supracitadas legislações orientam para que as estratégias de educação permanente sejam construídas de maneira pactuada, com o envolvimento de atores tanto do setor da saúde gestores, trabalhadores e usuários - como da educação - gestores, instituições de ensino, estudantes de cursos da área da saúde (Constituição Federal, 1988; Brasil, 1990, Brasil, 2004, Gigante \& Campos, 2016).

Amparados pela legislação vigente, Pereira e Oliveira (2013) ratificam a necessidade 
de que os setores da educação e da saúde estabeleçam parcerias interinstitucionais, a fim de desenvolver ações conjuntas que agreguem os conhecimentos produzidos e acumulados por ambas as áreas. Assim, buscando-se fazer essa articulação ensino-serviço, bem como possibilitar um espaço para problematização dos processos de trabalho, e das demandas vivenciadas pelos agentes comunitários de saúde, que o projeto de extensão do qual trata o presente artigo se efetivou.

O presente projeto está vinculado ao Departamento de Psicologia de uma Universidade Federal do Sul do Brasil, inicialmente se constituiu como um desdobramento de uma ação de extensão denominada "Intervenções precoces na infância: um projeto junto ao Programa da Criança de uma Unidade Básica de Saúde”. Esse projeto funciona aliado ao Programa de Atenção Integral à Saúde da Criança (Paisc) de uma unidade de saúde e tem como objetivo o acompanhamento de crianças de zero a dois anos em seu desenvolvimento físico e psíquico por profissionais e acadêmicos das áreas de Enfermagem e Psicologia, numa proposta interdisciplinar. Ao núcleo de Psicologia cabe, principalmente, a observação da relação paisbebê (ou aquela/aquele que cumpra a função de cuidador) de modo a detectar, prevenir e intervir precocemente em possíveis problemas e riscos relativos ao desenvolvimento infantil, valendo-se para isso dos Indicadores Clínicos de Risco ao Desenvolvimento Infantil - Irdi (Armiliato, 2014). Quando necessárias, são realizadas orientações para os pais que se encontram com dificuldades na relação com seus filhos, e no exercício e prática da parentalidade.
Nesse ínterim, durante a execução do referido projeto, a equipe de extensionistas e supervisores atentaram para a importância de se qualificar os profissionais da atenção básica acerca de temas envolvendo o desenvolvimento infantil e seus aspectos emocionais, assim como o exercício da parentalidade e as relações familiares. Constataram que especialmente os agentes comunitários de saúde poderiam participar dessa proposta de qualificação, visto que são profissionais estratégicos na identificação precoce de problemáticas de saúde da população, dada a proximidade que estabelecem com a comunidade a partir das visitas domiciliares. Com isso, foi proposta e efetivada a criação de um novo projeto de extensão que pudesse abordar essas e outras temáticas com os agentes comunitários de saúde a partir do olhar da Psicologia.

A ampliação e inserção desse núcleo profissional no campo da Saúde Pública é considerada emergente, visto que pode proporcionar diferentes discussões sobre as condições de saúde da população, expandir as possibilidades de cuidado, reconhecer os fatores subjetivos, a história e as condições de vida dos usuários, auxiliando assim na compreensão integral e contextualizada do indivíduo, das famílias e da comunidade (Böing, Crepaldi \& Moré, 2009; Lima, Brito \& Firmino, 2011).

Dessa forma, o objetivo deste artigo é relatar uma experiência de educação permanente em saúde com Agentes Comunitários de Saúde de um município do Rio Grande do Sul.

\section{Metodologia}

O presente projeto de extensão vem sendo realizado desde o segundo semestre de 
2013 com os ACS vinculados a uma Unidade Básica de Saúde, a qual está localizada na zona norte de um município do Rio Grande do Sul. São realizados encontros mensais de educação em saúde, com duração de aproximadamente uma hora e trinta minutos cada, nos quais são discutidas temáticas relacionadas às demandas trazidas pelos próprios agentes comunitários. Esses assuntos de interesse são levantados no início de cada semestre pelos agentes comunitários e podem ser revistos ao longo desse período, pois considera-se que a formação em saúde deve estar conectada com o trabalho que é realizado na comunidade e com a realidade vivida no cotidiano. Assim sendo, em algumas ocasiões, as coordenadoras do projeto também sugeriram e levantaram pautas de discussão consideradas relevantes para o cenário da prática em saúde.

Os encontros são coordenados por mestrandas vinculadas ao Programa de PósGraduação em Psicologia de uma universidade pública, as quais têm como papel não apenas transmitir conhecimentos e informações técnicas, mas, principalmente, fazer a mediação do grupo e a problematização de algumas questões levantadas utilizando metodologias ativas de ensino. Por metodologias ativas de ensino compreendemos, aqui, que estas englobam a utilização de conhecimentos e experiências reais ou simuladas, visando proporcionar condições de resolução dos desafios advindos das atividades da prática social e laboral dos profissionais (Berbel, 2011, Mitre et al., 2008, Roman et al., 2017). Nesse sentido, busca-se sempre a realização da troca de informações, experiências, e saberes através da reflexão e problematização, tanto do saber científico quanto da prática profissional, de forma a fomentar a dialética da ação-reflexão-ação
Atualmente participam dos encontros os ACS e a enfermeira responsável da UBS. Já participaram, e ainda participam eventualmente, acadêmicos de Medicina e Enfermagem vinculados a Instituições de Ensino Superior públicas e privadas, bem como outros profissionais da equipe, como médicos, enfermeiros e técnicos de enfermagem. Contudo, tais participações não são constantes em função das especificidades dos estágios e da dinâmica da unidade.

O projeto já passou por diversos formatos, sendo num primeiro momento voltado para as questões referentes ao desenvolvimento infantil (foco do projeto que lhe deu origem) e mais tarde foi sendo ampliado para as demandas trazidas pelos próprios profissionais. Dessa forma, até o presente momento foram discutidos assuntos como: Indicadores de Risco ao Desenvolvimento Infantil - Irdi (Kupfer et al., 2009; Kupfer et al., 2012); interação pais-bebê e desenvolvimento no primeiro ano de vida; relações familiares e desenvolvimento de crianças com algum tipo de deficiência física ou mental; amamentação; alergias e refluxo; violência contra crianças e adolescentes; desenvolvimento de crianças em idade pré-escolar, como fala e aprendizagem; separação conjugal e guarda compartilhada; gravidez na adolescência; saúde do trabalhador; direitos sociais dos usuários; saúde mental; violência contra idosos, além de discussões de casos com problemáticas relacionadas aos temas aqui expostos. Alguns encontros contaram com a participação de profissionais convidados, tais como: enfermeiros; psicólogos; profissionais da delegacia da mulher e do Centro de Referência da Assistência Social (Cras). Além disso, dependendo da temática 
abordada, foram desenvolvidos e disponibilizados materiais informativos que pudessem auxiliar os agentes e demais profissionais no seu fazer cotidiano.

Esses encontros têm se configurado como um momento em que, além de se discutir teoricamente sobre um determinado tema, os ACS trazem as experiências de trabalho, relatam casos, falam sobre suas dificuldades, limitações e frustrações do dia a dia. Dessa forma, os encontros são bastante flexíveis e dialogados, estando de acordo com o desejo e demanda dos participantes, considerando as vivências pessoais e profissionais de cada um.

\section{Resultados e discussões}

Inicialmente, como já salientado, o projeto de educação em saúde com os ACS surgiu por via de outro projeto de extensão realizado no Paisc. Ele tinha como objetivo construir um elo entre os ACS e o programa da criança, de modo a possibilitar um maior alcance das ações de promoção de saúde e prevenção de possíveis riscos ao desenvolvimento infantil.

Por conseguinte, em relação às temáticas abordadas, nos primeiros encontros foram discutidos temas que estavam diretamente ligados ao Programa da Criança e aos projetos de extensão e pesquisa lá realizados, com foco nos Irdis e no desenvolvimento do bebê no primeiro ano de vida (Arpini et al., 2015; Arpini et al., 2015b; Mozzaquatro, Arpini \& Polli, 2015; Armiliato, 2014; Fukuda, 2014). Entretanto, com o desenrolar dos encontros, os ACS ocuparam o seu lugar, redefinindo e ampliando a proposta inicial, dando uma "cara nova" ao projeto. A partir de então, os assuntos passaram a ser sugeridos pelos próprios agentes, segundo suas vivências na comunidade, o que pode ter contribuído para que se apropriassem e valorizassem essa experiência. Pode-se perceber que os agentes fizeram desse espaço um momento para pensar sobre as suas práticas, as suas vivências, as potencialidades do seu trabalho, bem como as frustrações que surgem com as limitações do cotidiano.

Perpassando todos os encontros realizados, a temática da vulnerabilidade social se fez presente. Os agentes relatam com pesar que muitas vezes se sentem impotentes e desmotivados perante diversas situações e problemáticas que enfrentam no dia a dia, para as quais as políticas públicas deveriam ser efetivadas, mas em grande parte dos casos não estão. Essas problemáticas englobam diversas outras esferas setoriais como assistência social, saúde mental, educação, entre outras. Sobre esse aspecto, no contexto comunitário, Bornstein, David e Araujo (2010) destacam que os problemas podem ser classificados segundo três níveis de intervenção: a) problemas passíveis de resolução com os meios disponíveis no serviço de saúde; b) problemas passíveis de resolução com os meios disponíveis na comunidade, dependendo de ação intersetorial; e c) problemas não solucionáveis no nível local, que dependem de articulações externas ou mesmo de políticas públicas. Duarte, Silva e Cardoso (2007) ratificam o discurso dos agentes por meio de uma analogia com o processo saúde-doença, referindo que muitas vezes os profissionais de saúde sentem-se impotentes diante dos determinantes sociais da saúde, deparando-se com problemas como a miséria, o desemprego, a violência, entre tantas outras situações para as quais não há solução 
imediata, mas que são tão graves que demandam ser cuidadas. A partir dessas premissas, Nascimento e Correa (2008) afirmam que para o trabalho dos agentes comunitários de saúde ser resolutivo é necessário que se efetive a intersetorialidade, devido à complexidade de problemas identificados incluir ações que extrapolam a autonomia e governabilidade da área de saúde.

Nessa mesma perspectiva, o grupo também trouxe a questão da insegurança e da vulnerabilidade a que estão expostos diante de situações difíceis em que necessitam intervir. Pode-se perceber que as situações que envolvem violência nas relações familiares e violação de direitos são aquelas que mobilizam mais temores e dificuldades quanto a seu enfrentamento. Sentimentos como medo e apreensão parecem fazer parte do cotidiano de trabalho, tendo em vista que os ACS são sujeitos que residem na própria comunidade e estão, portanto, mais vulneráveis aos efeitos que podem resultar das reações provocadas pelas medidas de enfrentamento dessas situações, como denúncia, encaminhamento ao Conselho Tutelar e/ou outros serviços da rede Suas ou SUS. Nesse sentido, estudos vêm indicando a importância do trabalho em equipe e do suporte institucional perante o trabalho com a violência (Arpini, Forno, Hermann \& Soares, 2010; Serra, Carvalho \& Magalhães, 2014).

Ficou bastante evidente também a complexidade da função de ser o mediador entre a comunidade e a equipe de saúde e entre os saberes populares e os científicos. De acordo com Piccinini e Neves (2013), a dimensão social convivendo com a dimensão técnica assistencial é um dilema permanente no trabalho do agente comunitário. Conforme os autores, a expectativa de que os ACS realizem essa mediação/tradução entre os saberes científicos e populares é algo que se torna complexo, na medida em que se consideram os níveis de formação e os diversos saberes que compõem cada território. Essa complexidade é apontada como um dos principais motivos para que a responsabilidade de mediação e aproximação da comunidade não recaia somente para os ACS, sendo fundamental que toda a equipe assuma a tarefa de cuidar do usuário, reconhecendo que para abordar a complexidade do trabalho em saúde são necessários diferentes olhares, saberes e fazeres (Brasil, 2009).

Ainda em relação à articulação e aproximação dos saberes, foi possível perceber nas discussões com o grupo que alguns saberes e fazeres estão rígidos e cristalizados na compreensão de saúde dos ACS. Pode-se perceber uma certa resistência a mudanças nos processos de trabalho, pois, por vezes, o discurso queixoso fica fortalecido e as possibilidades de intervenções inovadoras enfraquecidas. Além disso, muitas vezes o discurso do senso comum norteia as ações e intervenções desses profissionais, levando com que eles acabem reproduzindo preconceitos e juízos de valor acerca da vida dos usuários, numa perspectiva moralizadora. Brigadão e Gonçalves (2009), em suas experiências com oficinas de promoção de saúde com agentes comunitários, perceberam também uma certa dificuldade destes em romper com o modelo tradicional de cuidado, que é majoritariamente focado no indivíduo e na responsabilização e culpabilização do agente por sua situação de vida e saúde. Os autores (2009, p. 392) atentam para "a importância de se considerar 
que os agentes 'promotores' de saúde também são indivíduos que trazem consigo suas histórias e experiências que permanecem presentes no cotidiano de suas vidas permeando suas práticas profissionais". Nesse sentido, entender e trabalhar essa dinâmica e essa forma de interação/relação serviço-comunidade-usuárioprofissional, pode auxiliar na superação de preconceitos e no processo de transformação social (Brigadão \& Gonçalves, 2009).

Assim sendo, ao longo dos encontros, buscou-se com as discussões com o grupo transformar as situações cotidianas em aprendizagem por meio da reflexão dos problemas da prática, valorizando os processos de trabalho, especialmente o trabalho em equipe e em rede. Aproximar a educação da vida cotidiana é consequência de um reconhecimento das potencialidades da educação em trabalho. É reconhecer que o processo de educação vai além da transmissão de conhecimento científico, podendo ser um espaço para se problematizar o fazer saúde e, com isso, encontrar estratégias para sua transformação (Davini, 2009). É entender a educação como problematização da realidade e também como possibilidade de autoconhecimento e de mudanças (Pereira \& Oliveira, 2013).

Em um dos encontros, uma das agentes referiu que o "espaço com a Psicologia", como eles chamam, era o momento em que ela podia falar, podia desabafar todo o sentimento e angústia que é preciso reprimir para continuar trabalhando, porque a Psicologia estava ali para escutar e ajudar a pensar. Essa escuta constitui-se em um momento de alívio de angústias, na medida em que os ACS se sentem acolhidos e com possibilidade de compartilhar as dificuldades cotidianamente enfrentadas. Além disso, com esse recorte, pode-se perceber o potencial que esses encontros têm como espaços de promoção de saúde dos trabalhadores, em especial, dos ACS, no sentido de que ali existe um lugar para eles, onde há a possibilidade de ressignificar as suas vivências na comunidade.

Ademais, a prática extensionista é um processo formativo de transformação para todos os envolvidos, tanto para os profissionais da unidade, para as mestrandas que coordenam o grupo quanto para os docentes orientadores. Lima, Brito e Firmino (2011) colocam que projetos de extensão oportunizam uma formação fora do contexto estritamente universitário, o que pode significar uma oportunidade de qualificar os(as) psicólogos(as) para atuarem profissionalmente, neste caso, no SUS, considerando que a formação em Psicologia indica, nas Novas Diretrizes Curriculares Nacionais para os Cursos de Graduação em Psicologia, que "As atividades de extensão devem ser articuladas com o protagonismo dos sujeitos e de seus coletivos, ocorrer de forma territorializada, supervisionada e continuada, e dialogar com as políticas públicas" (CFP, 2018, p. 128). Em concordância com essa perspectiva e com a afirmativa dos autores, consideramos que com as trocas realizadas não apenas os profissionais de saúde, mas também os profissionais em formação acadêmica puderam ressignificar suas vivências, práticas e 
visão sobre o mundo. A esse respeito, Paulo Freire (1993, p. 88) exprime com clareza o significado dos momentos compartilhados dizendo que

Ninguém nasce feito. Vamos nos fazendo aos poucos na prática social de que tomamos parte. [...] Vim me tornando desta forma no corpo das tramas, na reflexão sobre a ação, na observação atenta a outras práticas ou à prática de outros sujeitos. [...] É impossível ensaiarmos estar sendo deste modo sem uma abertura crítica aos diferentes e às diferenças, com quem e com que é sempre provável aprender.

\section{Considerações finais}

Com a realização dos encontros, tem sido possível perceber a importância e a complexidade do trabalho dos Agentes Comunitários de Saúde. Essa complexidade refere-se tanto à parte prescrita a ser realizada por eles, como ações de promoção de saúde, prevenção de doenças e agravos, ações educativas e de orientação por meio de visitas domiciliares, como também a sensibilidade inerente a este trabalho e que vem sendo inventado no ato, por meio das relações que os ACS estabelecem com os indivíduos e as coletividades.

Além disso, os ACS deparam-se diariamente com condições de vida precárias, desigualdades sociais, violências e criminalidades. $\mathrm{O}$ que, no caso dos ACS que participam dos encontros de educação em saúde, ocasiona conflitos entre a sua vida pessoal, como morador(a) daquele território, e sua função profissional, como trabalhador(a) da equipe de saúde. Consideramos que, muitas vezes, os conflitos entre a vida pessoal e sua função técnica acabam gerando angústias e sofrimentos. Dessa forma, destaca-se a importância de espaços que possibilitem a reflexão e a problematização das experiências vividas, pois foi possível observar o potencial que esses encontros têm de aliviar angústias e promover saúde mental a esses trabalhadores.

Essa proposta tem permitido também a ampliação do olhar sobre as temáticas trabalhadas, favorecendo a realização de um trabalho reflexivo, ético e humano. Além disso, as atividades desenvolvidas têm possibilitado uma articulação entre os acadêmicos e os profissionais, bem como entre a graduação e a pós-graduação. Por fim, destaca-se a importância da realização desta e de outras ações que busquem superar a fragmentação e a compartimentalização dos saberes, a fim de qualificar cada vez mais o cuidado em saúde, de forma que ele se aproxime dos pressupostos do SUS. Neste artigo procuramos enfocar a prática da Psicologia nesse contexto, contudo, entende-se que ações dessa natureza se constituem como campo de todas as profissões envolvidas com a atenção básica e que ações de caráter interdisciplinar envolvendo a educação permanente são desafios importantes a serem enfrentados pelos diferentes núcleos profissionais. Salienta-se, assim, que uma das limitações desta experiência se deve ao fato de estar circunscrita a um contexto específico, destacando-se, dessa forma, a importância de outras experiências considerando a diversidade da realidade brasileira e a importância estratégica que os agentes comunitários ocupam no cenário da política de saúde na atenção básica. 


\section{Referências}

Alencar, C. A. B., de Oliveira, M. A., Belém, J. M., Parente, J. S., \& Albuquerque, G. A. (2015). Conhecimento de agentes comunitários de saúde acerca do Sistema Único de Saúde e sua operacionalização - Araripina, Pernambuco. $S A N A R E$ - Revista de Políticas Públicas, 13(2).

Armiliato, V. (2014). Irdi: Implementação de uma ferramenta psicanalítica no âmbito das políticas públicas. In M. C. M. Kupfer, L. M. Bernardino \& R. M. Mariotto (Org.). De bebê a sujeito: a metodologia Irdi nas creches (pp. 83-94). São Paulo: Escuta/Fapesp.

Arpini, D. M., Marchesan, R. Q., Zanatta, E. Savegnago, S. D. O., Bernardi, P. H. (2015). Intervenções precoces na infância: observando a relação mãe-bebê em um serviço de saúde. Psicologia em Revista, 21(1), 37-49.

Arpini, D. M., Zanatta, E., Mozzaquatro, C., Ledur, C, Z., Marcehsan, R. Q., Faraj, S. P. (2015). Interação pais-bebê: um processo de descobertas. Interação em Psicologia, 19(1), $1-11$.

Arpini, D. M., Forno, C. D., Hermann, C., \& Soares, A. C. O. (2010). A importância da escuta na revelação da violência contra a infância e adolescência. Psicologia, Educação e Cultura, 14(1), 111-128.

Berbel, N. A. N. (2011). As metodologias ativas e a promoção da autonomia de estudantes. Semina: Ciências Sociais e Humanas, Londrina, 32(1), 25-40.

Barros, D. F., Barbieri, A. R., Ivo, M. L. \& Silva, M. (2010). O contexto da formação dos agentes comunitários de saúde no Brasil. Texto contexto - enferm. [online], 19(1), 78-84. ISSN 0104-0707.

Böing, E., Crepaldi, M. A., \& Moré, C. L. O. O. (2009). A epistemologia sistêmica como substrato à atuação do psicólogo na atenção básica. Psicologia Ciência e Profissão, 29(4), 828-845.

Bornstein, V. J., David, H. M. S. L., \& Araujo, J. W. G. (2010). Agentes comunitários de saúde: a reconstrução do conceito de risco no nível local. Interface [online], 14(32), 93101. ISSN 1414-3283.

Brasil. (2006). Ministério da Saúde. Secretaria de Atenção à Saúde. Departamento de Atenção Básica. Política nacional de atenção básica / Ministério da Saúde, Secretaria de Atenção à Saúde, Departamento de Atenção à Saúde. Brasília: Ministério da Saúde.

Brasil. (2007b). Fórum da Reforma Sanitária Brasileira. A Reforma Sanitária é uma Reforma Solidária. Boletim do Fórum da Reforma Sanitária Brasileira. Brasília. Divulgado durante a $13^{\mathrm{a}}$ Conferência Nacional de Saúde em dez. 2007.

Brasil. (2009). Ministério da Saúde. Secretaria de Atenção à Saúde. Departamento de Atenção Básica. O trabalho do agente de saúde. Ministério da Saúde, Secretaria de Atenção 
à saúde, Departamento de Atenção Básica.

Brasília: Ministério da Saúde.

Brasil. (2011b). Ministério da Saúde. O SUS de A a Z: Garantindo saúde nos municípios / Ministério da Saúde, Conselho Nacional de Secretárias Municipais de Saúde. 3 ed. Brasília: Editora do Ministério da Saúde.

Brasil. (2012). Ministério da Saúde. Secretaria de Atenção à Saúde. Departamento de Atenção Básica. Política Nacional de Atenção Básica. Brasília: Ministério da Saúde.

Brasil. (2017). Ministério da Saúde. Secretaria de Atenção À Saúde. Departamento de Atenção Básica. Política Nacional de Atenção Básica / Ministério da Saúde, Secretaria de Atenção à Saúde, Departamento de Atenção Básica. Brasília: Ministério da Saúde.

Brigadão, J. I. M., \& Gonçalves, R. (2009). Oficinas de promoção de saúde: discutindo os dilemas do cotidiano de um grupo de agentes comunitárias de saúde. Paideia, 19(44), 387-393.

Conselho Federal de Psicologia (2018). Revisão das Diretrizes Curriculares Nacionais para os Cursos de Graduação em Psicologia.

Constituição da República Federativa do Brasil de 1988. (1988). Brasília: Senado Federal.

Davini, M. C. (2009). Enfoques, problemas e perspectivas na educação permanente dos Recursos Humanos de Saúde. In Brasil, Ministério da Saúde. Política Nacional de
Educação Permanente em Saúde (Textos Básicos de Saúde, Vol. 9, pp. 39-63). Brasília: Ministério da Saúde.

Duarte, L. R., Silva, D. S. J. R., \& Cardoso, S. H. (2007). Construindo um programa de educação com agentes comunitários de saúde. Interface [online], 11(23), 439-447. ISSN 1414-3283.

Figueiredo, M. D. (2012). A construção de práticas ampliadas e compartilhadas em saúde: apoio Paideia e formação. Tese de doutorado em Saúde Coletiva, Faculdade de Ciências Médicas, Universidade Estadual de Campinas, Campinas.

Freire, P. (1993). Política e educação. São Paulo: Cortez.

Fukuda, J. E. (2014). Considerações a respeito da prevenção em saúde mental na primeira infância. In M. C. M. Kupfer, L. M. Bernardino \& R. M. Mariotto (Org.). De bebê a sujeito: a metodologia Irdi nas creches (pp. 25-32). São Paulo: Escuta/Fapesp.

Gigante, R. L., \& Campos, G. W. de S. (2016). Política de formação e educação permanente em saúde no Brasil: bases legais e referências teóricas. Trabalho, Educação e Saúde, 14(3), 747-763. Recuperado de https://dx.doi.org/10.1590/1981-7746$\operatorname{sip} 00124$

Kupfer, M. C. M., Bernardino, L. M. F., Jerusalinsky, A. N., Rocha, P. S. B., Lerner, R., \& Pesaro, M. E. (2008). A pesquisa Irdi: resultados finais. In M. C. M. Kupfer \& R. 
Lerner (Org.). Psicanálise com crianças: clínica e pesquisa (pp. 221-230). São Paulo: Editora Escuta Ltda.

Kupfer, M. C. M., Jerusalinsky, A. N., Bernardino, L. M. F., Wanderley, D. B., Rocha, P. S. B., Molina, S. E., Sales, L. M. M., Stellin, R. M. R., Pesaro, M. E., \& Lerner, R. (2009). Valor preditivo de indicadores clínicos de risco para o desenvolvimento infantil: um estudo a partir da teoria psicanalítica. Latin American Journal of Fundamental Psychopathology On Line, 6(1), 46-68.

Kupfer, M. C. M., Bernardino, L. M. F., Mariotto, R. M. M., Pesaro, M. E., Lajonquière, L., Voltolini, R., \& Machado, A. M. (2012). Metodologia Irdi: uma ação de prevenção na primeira infância. In M. C. M. Kupfer, L. M. F. Bernardino \& R. M. M., Mariotto (Org.). Psicanálise e acões de prevenção na primeira infância (pp. 131-145). São Paulo: Escuta/Fapesp.

Gomes, K. D. O., Cotta, R. M. M., Cherchiglia, M. L., Mitre, S. M., \& Batista, R. S. (2009). A práxis do agente comunitário de saúde no contexto do programa saúde da família: reflexões estratégicas. Saúde Soc., São Paulo, 18(4), 744-755.

Leite, A. L. S., \& Paulon, S. (2013). Atenção Básica e desinstitucionalização da loucura: acionando competências dos Agentes Comunitários de Saúde. In S. Paulon \& R. Neves (Org.). Saúde Mental na Atenção Básica: a territorialização do cuidado (pp. 99112). Porto Alegre: Editora Sulina.
Lima, M., Brito, M. \& Firmino, A. (2011). Formação em Psicologia para a Atenção Básica à Saúde e a Integração Universidade-Serviço-Comunidade. Psicologia Ciência e Profissão, 31(4), 856-867.

Lei n. 8.080, de 19 de setembro de 1990. (1990). Dispõe sobre as condições para a promoção, proteção e recuperação da Saúde, a organização e o funcionamento dos serviços correspondentes e dá outras providências. Diário Oficial da União, Brasília, DF.

Lei n. 8.142, de 28 de dezembro de 1990. (1990). Dispõe sobre a participação da comunidade no SUS. Diário Oficial da União, Brasília, DF.

Lopes, M. R, Durão, A. V., \& Carvalho, V. (2011). A disputa sobre os sentidos do trabalho e da formação dos agentes comunitários de saúde. In M. Vieira, A. V. Durão \& M. R. Lopes (Org.). Para além da comunidade: trabalho e qualificação dos Agentes Comunitários de Saúde (pp. 161-208). Rio de Janeiro: EPSJV.

Mitre, S. M, Siqueira-Batista, R., Girardi-deMendonça, J. M., Morais-Pinto, N. M. de, Meirelles, C. A. B., Pinto-Porto, C., Moreira, T., \& Hoffmann, L. M. A. (2008). Metodologias ativas de ensino aprendizagem na formação profissional em saúde: debates atuais. Ciência \&o Saúde Coletiva, 13(2), 2133-2144.

Morosini, M. V. G., Fonseca, A. F., \& Lima, L. D. (2018). Política Nacional de Atenção 
Básica 2017: retrocessos e riscos para o Sistema Único de Saúde. Saúde debate, 42(116), 11-24.

Motta, L. C. de S., \& Siqueira-Batista, R. (2015). Estratégia Saúde da Família: Clínica e Crítica. Revista Brasileira de Educação Médica, 39(2), 196-207. Recuperado de https://dx.doi.org/10.1590/1981$52712015 v 39$ n2e00912014.

Mozzaquatro, C. O., Arpini, D. M., Polli, R. G. (2015). Relação mãe-bebê e promoção de saúde no desenvolvimento infantil. Psicologia em Revista, 21(1), 333-350.

Nascimento, E. P. L., \& Correa, C. R. S. (2008). O agente comunitário de saúde: formação, inserção e práticas. Cad. Saúde Pública [online], 24(6), 1304-1313. ISSN 0102-311X

Nogueira, R. P., Silva, F. B., \& Ramos, Z. V. O. (2000). A vinculação institucional de um trabalhador sui generis: o agente comunitário de saúde. Rio de Janeiro: Instituto de Pesquisa Econômica Aplicada. (Texto para Discussão, 735).

Nunes, M. de O., Trad, L. B, Almeida, B. de A., Homem, C. R., \& Melo, M. C. I. de C. (2002). O agente comunitário de saúde: construção da identidade desse personagem híbrido e polifônico. Cadernos de Saúde Pública, 18(6), 1639-1646. Recuperado de https://dx.doi.org/10.1590/S0102$311 \times 2002000600018$
Pereira, I. C., \& Oliveira, M. A. de C. (2013). O trabalho do agente comunitário na promoção da saúde: revisão integrativa da literatura. Revista Brasileira Enfermagem, $66(3), 412-419$.

Piccinini, C. A., \& Neves, R. (2013). A saúde bate à sua porta: olhares sobre a prática dos Agentes Comunitários de Saúde. In S. Paulon \& R. Neves (Org.). Saúde Mental na Atenção Básica: a territorialização do cuidado (pp. 83-98). Porto Alegre: Editora Sulina.

Portaria GM/MS n. 198/2004, de 13 de fevereiro de 2004. (2004). Institui a política nacional de educação permanente em saúde como estratégia do Sistema Único de Saúde para a formação e o desenvolvimento de trabalhadores para o setor e dá outras providências. Ministério da Saúde. Recuperado de www.saude.gov.br/sgtes.

Portaria n. 2.488, de 21 de outubro de 2011. (2011). Aprova a Política Nacional de Atenção Básica, estabelecendo a revisão de diretrizes e normas para a organização da Atenção Básica, para a Estratégia Saúde da Família (ESF) e o Programa de Agentes Comunitários de Saúde (PACS). Brasília, DF: Diário Oficial da União: Ministério da Saúde.

Roman, C., Ellwanger, J., Becker, G. C., Silveira, A. D. D., Machado, C. L. B., \& Manfroi, W. C. (2017). Metodologias ativas de ensinoaprendizagem no processo de ensino em saúde no Brasil: uma revisão narrativa. Clinical and Biomedical Research, 37(4), 349-357. 
Serra, A. S., Carvalho, L. C., \& Magalhães, M. L. (2014). Atenção Integral a saúde de crianças e de adolescentes em situação de violência sexual, em linhas de cuidado. In B. R. dos Santos, I. B. Gonçalves, M. G. Vasconcelos, P. B. Barbiéri \& V. N. Viana (Org.). Escuta de crianças e adolescentes em situação de violência sexual: aspectos teóricos e metodológicos (pp. 147-166). Brasília: EdUCB.

Silva, J. A. da, \& Dalmaso, A. S. W. (2002). O agente comunitário de saúde e suas atribuições: os desafios para os processos de formação de recursos humanos em saúde. Interface: Comunicaşão, Saúde, Educação, 6(10), 75-94.

Souza, R. F., \& Abrahão, A. L. (2017). Reflexão sobre o processo de trabalho na estratégia saúde da familia (ESF). Revista Labor, 1(3), 82-95.

Souza, M. C. M. R., Barcelos, A. P. M., \& Lanza, F. M. (2014). A política de formação técnica do agente comunitário de saúde: perspectivas e desafios. Revista de APS, 16(4).

Recebido em: 14/9/2017

Aprovado em: 8/10/2018 